\title{
EFFECT OF HYDROCARBON CHAIN LENGTH ON ADSORPTION OF CATIONIC SURFACTANTS ONTO CLINOPTILOLITE
}

\author{
Bahri Ersoy ${ }^{1, *}$ and Mehmet S. Çelik ${ }^{2}$ \\ ${ }^{1}$ Afyon Kocatepe University, Afyon Vocational High School, 03200 Afyon, Turkey \\ 2 İstanbul Technical University, Mining Faculty, Minerals and Coal Processing Section, Ayazaga 80626, Istanbul, Turkey
}

\begin{abstract}
The adsorption behavior of quaternary ammonium cationic surfactants with different hydrocarbon chain lengths, i.e. HDTMA (hexadecyltrimethylammonium), TDTMA (tetradecyltrimethylammonium) and DDTMA (dodecyltrimethylammonium), onto clinoptilolite has been investigated. The adsorption isotherms of these surfactants are correlated with the $\zeta$ potential curves of clinoptilolite. Accordingly, the applicability of the hemimicelle hypothesis to the adsorption of cationic surfactants at the clinoptilolite/water interface considering in the electrical double layer (EDL) of clinoptilolite is discussed. Even though the adsorption occurs in the EDL of clinoptilolite, the adsorption of HDTMA, TDTMA and DDTMA onto clinoptilolite is not conveniently described by the hemimicelle hypothesis. The absence of all expected marked increase in the $\zeta$ potential curves at the hemimicelle concentration is ascribed to the large external cation exchange capacity (ECEC) of clinoptilolite. The hydrocarbon chain length of surfactant molecules is found to have a significant effect on the ion exchange as well as hydrophobic interaction mechanisms. The effectiveness of both ion exchange and hydrophobic interactions increases with increasing chain length, and so the greatest surfactant adsorption onto clinoptilolite was obtained by HDTMA.
\end{abstract}

Key Words-Adsorption, Cationic Surfactant, Clinoptilolite, Double Layer, Hydrophobic Interaction, Ion Exchange, $\zeta$ Potential.

\section{INTRODUCTION}

Clinoptilolite is one of the most common and abundant natural zeolite minerals with a three-dimensional crystal structure and typical unit-cell formula of either $\mathrm{Na}_{6}\left[\left(\mathrm{AlO}_{2}\right)_{6}\left(\mathrm{SiO}_{2}\right)_{30}\right] .24 \mathrm{H}_{2} \mathrm{O}$ or $\left.\left(\mathrm{Na}_{2}, \mathrm{~K}_{2}, \mathrm{Ca}, \mathrm{Mg}\right)_{3}\left[\left(\mathrm{AlO}_{2}\right)_{6}\left(\mathrm{SiO}_{2}\right)_{30}\right] .24 \mathrm{H}_{2} \mathrm{O}\right]$ (Breck, 1974; Haggerty and Bowman, 1994). It exhibits regular two-dimensional channel systems represented by A, B and $C$ with opening sizes of $7.2 \times 4.4,4.7 \times 4.1$ and $5.5 \times 4.0 \AA$, respectively (Merkle and Slaughter, 1968; Alberti, 1975; Mortier and Pearce, 1981; Ackley and Yang, 1991). In these channels, exchangeable cations such as $\mathrm{Na}, \mathrm{K}, \mathrm{Ca}$ and $\mathrm{Mg}$ are amenable to ion exchange with organic and inorganic cations (Ames, 1960; Barrer et al., 1967; Blanchard et al., 1984; Ersoy, 2000).

Cationic surfactants are generally used in the textile, agriculture, dye, cosmetics, chemical and mining industries for various purposes (Leja, 1982; Brownawell et al., 1990; Flanigen, 1991; Li et al., 1998). More importantly, the quaternary amines are typically used to modify hydrophilic mineral surfaces $e . g$. of clay and some natural zeolites which are known as organo clay (OC) and organo zeolite (OZ), respectively ( Haggerty and Bowman, 1994; Nzengung et al., 1997). The OC and $\mathrm{OZ}$ minerals are capable of removing toxic non-ionic organic contaminants such as benzene, toluene, ethyl-

* E-mail address of corresponding author: bersoy@aku.edu.tr DOI: 10.1346/CCMN.2003.0510207 benzene, xylene (referred to collectively as BTEX), tetrachloromethane, aniline, nitrobenzene, and inorganic anionic contaminants such as chromate, sulfate, selenate from waters and wastewaters (Lee et al., 1989; Smith et al., 1990; Neel, 1992; Haggerty and Bowman, 1994; Hayworth and Burris, 1997; Zhu et al., 1997; Gitipour et al., 1997; Jaynes and Vance, 1999; Sheng and Boyd, 1998; 2000; Ersoy, 2000).

Adsorption mechanisms of quaternary ammonium cationic surfactants onto different clay, earth and zeolite (clinoptilolite) minerals have been examined in a number of studies. The adsorption mechanisms have been explored by conventional adsorption isotherms (Lee et al., 1989; Patzko and Dekany, 1993; Haggerty and Bowman, 1994; Bowman et al., 1995; Xu and Boyd, 1995; Li and Bowman, 1997; Sabah and Çelik, 2002), calorimetric (Sullivan et al., 1998a), spectroscopic (Gitipour et al., 1997; Chen et al., 1998; Sullivan et al., 1998b), and microscopic (Sullivan et al., 1997) techniques. Two major mechanisms are proposed for the adsorption of cationic surfactants onto different clay, earth and zeolite minerals: ion exchange and hydrophobic interaction. The parameters governing the interactions between a surfactant molecule and an adsorbent with ion-exchange capability are: (1) the structure of adsorbent, i.e. hydrophilicity or hydrophobicity, surface potential and sign of the surface, porosity, ion exchange capacity, surface heterogeneity; (2) the structure of adsorbate, i.e. type of surfactant (ionic or non-ionic, aromatic or aliphatic), hydrocarbon chain length (linear or branched), and for ionic surfactant, its polar group; 
and (3) solution conditions ( $\mathrm{pH}$, temperature, polarity, dielectric constant, and ionic strength), are given in a number of publications (Somasundaran et al., 1964; Somasundaran and Fuerstenau, 1966; Narine and Guy, 1981; Leja, 1982; Xu and Boyd, 1985; Bowman et al., 1995; Sridharan and Satyamurty, 1996; Li and Bowman, 1997; Pavan et al., 1998; Chen et al., 1998).

In order to identify the most appropriate modification conditions for clinoptilolite, it is necessary to take into account the hydrocarbon chain length of the surfactant. Therefore, it is important to select surfactants with different chain lengths. Numerous studies of clay or earth minerals have been carried out, some of which are adsorption of HDTMA and DDTMA on montmorillonite (Chen et al., 1998), adsorption of HDTMA, TDTMA and NTMA (nonyltrimethylammonium) onto different earth minerals (Lee et al., 1989), adsorption kinetics of HDTMA, TDTMA, DDTMA at the silica/water interface (Biswas and Chattoraj, 1998), and adsorption of ten different types of quaternary ammonium compounds onto bentonite (Smith et al., 1990). Chen et al. (1998) pointed out that HDTMA yields greater adsorption than DDTMA. Lee et al. (1989) showed that soil modified with HDTMA is most effective in removing the aromatic-type organic contaminants. Biswas and Chattoraj (1998) determined that the diffusion coefficients of surfactants from bulk solution into the silica/ water interface are in the order HDTMA > TDTMA > DDTMA. Smith et al. (1990) showed that an increase in chain length of the modifier surfactant of bentonite enhanced the adsorption capacity of non-ionic contaminant. Although systematic studies relevant to the effect of surfactant chain length on adsorption have been covered for some clay and soil minerals, none on clinoptilolite has been found in the literature. In three quarters of the studies of adsorption of cationic surfactants onto clinoptilolite, only HDTMA was used as a cationic surfactant (Haggerty and Bowman, 1994; Sullivan et al., 1997; Li and Bowman, 1997, 1998; Li et al., 1998; Sullivan et al., 1998b). Sullivan et al. (1998a) used HDTMA and TEA (tetraethylammonium) but the difference in their polar groups and their hydrocarbon chain length make it difficult to ascertain the effect of chain length on adsorption.

It is well known in the literature that $\zeta$ potential is an excellent tool for observation and description of surface reactions at the mineral/water interface (Hunter, 1988). Therefore $\zeta$ potential data have been used for explaining the adsorption mechanisms of ionic surfactants (Somasundaran et al., 1964; Somasundaran and Fuerstenau, 1966; Xu and Boyd, 1995), and in particular for examining the effect of chain length on surfactant adsorption at the mineral/water interfaces (Somasundaran et al., 1964; Çelik and Yoon, 1991). No study relevant to the adsorption of quaternary amines at the clinoptilolite/water interface was found in the literature.
The aim of this study was, therefore, to examine systematically the effect of chain length on the adsorption of cationic surfactants of homolog series onto clinoptilolite by correlating adsorption isotherms with $\zeta$ potential curves and to determine whether the hemimicelle hypothesis can account for the adsorption mechanism.

\section{EXPERIMENTAL PROCEDURE}

\section{Materials}

The clinoptilolite sample from the Gordes Region of Turkey was supplied by the Incal company. The mineralogical analysis by X-ray diffraction (XRD) analysis (Rigaku Rint-2000) using $\mathrm{CuK} \alpha$ radiation indicated 92\% clinoptilolite, $4.5 \%$ smectite, $2.5 \%$ cristobalite and $1 \%$ mica. Chemical analysis of the sample determined by X-ray fluorescence (XRF) (Rigaku X-2000) indicated $73.28 \% \mathrm{SiO}_{2}, 11.70 \% \mathrm{Al}_{2} \mathrm{O}_{3}, 2.16 \% \mathrm{CaO}, 0.90 \% \mathrm{MgO}$, $3.14 \% \mathrm{~K}_{2} \mathrm{O}, 0.45 \% \mathrm{Na}_{2} \mathrm{O}, 0.99 \% \mathrm{Fe}_{2} \mathrm{O}_{3}, 0.09 \% \mathrm{TiO}_{2}$ with $7.29 \%$ loss on ignition. Since $\mathrm{K}^{+}$is the major exchangeable cation in the clinoptilolite sample, it is referred as $\mathrm{K}$ clinoptilolite. The sample was ground for $1.5 \mathrm{~h}$ in a ball mill and passed through a $100 \mu \mathrm{m}$ sieve and this sample was used for BET analysis and all other experiments. The external surface area of clinoptilolite was measured as $16.73 \mathrm{~m}^{2} / \mathrm{g}$ by the BET technique (Micromeritics Flowsorb II-2300). This external surface area value was used in calculating the area occupied by each surfactant molecule. The crystal structure of clinoptilolite was examined by means of scanning electron microscopy (SEM) (Jeol JSM-T330), and its thermal stability by differential thermal analysis (DTA) (Netsch Geratebau Gmbh-404). Since the structures of clinoptilolite and heulandite are very similar, the absence of a peak at $700-800^{\circ} \mathrm{C}$ on the DTA curve indicated the presence of clinoptilolite. A modified form of the Ming and Dixon (1987) method (Haggerty and Bowman, 1994) was utilized to determine the external cation exchange capacity (ECEC) and the total CEC of the clinoptilolite sample at 8.5 and $172 \mathrm{cmol} / \mathrm{kg}$, respectively. The cations released into the solution from clinoptilolite during the CEC and ECEC measurements were analyzed by inductively coupled plasma mass spectrometry (ICP-MS).

The quaternary ammonium compounds of different hydrocarbon chain length used in this work are hexadecyltrimethylammonium bromide [HDTMA-Br, $\mathrm{C}_{16} \mathrm{H}_{33}\left(\mathrm{CH}_{3}\right)_{3} \mathrm{NBr}$, Aldrich Chem. Co., 99\% purity], Tetradecyltrimethylammonium bromide [TDTMA-Br, $\mathrm{C}_{14} \mathrm{H}_{29}\left(\mathrm{CH}_{3}\right)_{3} \mathrm{NBr}$, Sigma Chem. Co., 99\% purity] and dodecyltrimethylammonium bromide [DDTMA-Br, $\mathrm{C}_{12} \mathrm{H}_{25}\left(\mathrm{CH}_{3}\right)_{3} \mathrm{NBr}$, Sigma Chem. Co., 99\% purity]. The $\mathrm{Br}$ salts of surfactants were selected because $\mathrm{Li}$ and Bowman (1997) found that the adsorption of HDTMA$\mathrm{Br}$ onto clinoptilolite is more stable than that of HDTMA-HSO ${ }_{4}$ and HDTMA-Cl. In order to determine the critical micelle concentration (CMC) of HDTMA, 
TDTMA and DDTMA, surface tension measurements were carried out using a 'KRÜS Gmbh model K6' tensiometer with the ring method. The CMC values for the above surfactants are $1.0 \times 10^{-3}, 3.5 \times 10^{-3}$ and $1.5 \times 10^{-2} \mathrm{~mol} / \mathrm{L}$, respectively, in good agreement with the values given in the literature (Leja, 1982). The other organic and inorganic chemicals used in this work are as follows: sodium dodecylsulfate (SDS, $\mathrm{C}_{12} \mathrm{H}_{25} \mathrm{NaO}_{4} \mathrm{~S}$, Fluka Chem., 98.5\% purity) used as a titrant in the volumetric analysis of quaternary amines; disulfine blue (Fluka), dimidiumbromide (Sigma), ethanol (Aksin Chem.), chloroform (Aksin Chem.), $\mathrm{H}_{2} \mathrm{SO}_{4}, 1 \mathrm{~N} \mathrm{HCl}$ and $1 \mathrm{~N} \mathrm{NaOH}$ used for $\mathrm{pH}$ adjustments; and $\mathrm{CaCl}_{2} \cdot 2 \mathrm{H}_{2} \mathrm{O}, \mathrm{NaCl}$ and $\mathrm{Al}\left(\mathrm{NO}_{3}\right)_{3} \cdot 9 \mathrm{H}_{2} \mathrm{O}$ (as a standard solution of $1000 \mathrm{ppm}$ ) used in the adsorption experiments. All the organic and inorganic chemicals used in this study were of analytical grade. Throughout the experimental work, distilled water with a conductivity of $1.5 \mu \mathrm{mhos} / \mathrm{cm}$ was used.

\section{Methods}

The adsorption experiments were conducted with stock solutions of $5 \times 10^{-2} \mathrm{M}(\mathrm{mol} / \mathrm{L})$ of HDTMABr, TDTMABr and DDTMABr in distilled water. Next, the solutions of $20 \mathrm{~mL}$ at different initial concentrations ranging from $1 \times 10^{-3}$ to $3 \times 10^{-2} \mathrm{M}$ were prepared out of the stock solutions and placed into $50 \mathrm{~mL}$ polycarbonate centrifuge tubes. $1 \mathrm{~g}$ of clinoptilolite was added to each tube. The tubes were closed with screw caps and conditioned on a shaker at $25^{\circ} \mathrm{C}$ at $400 \mathrm{rpm}$ for $2 \mathrm{~h}$ in order to reach equilibrium. The adsorption of surfactant was found to reach equilibrium in $\sim 30 \mathrm{~min}$. Allowing for extreme cases of concentration and $\mathrm{pH}$, a $2 \mathrm{~h}$ period of conditioning time was selected. The mixtures were then centrifuged at $3500 \mathrm{rpm}$ for $15 \mathrm{~min}$ to obtain a clear supernatant. Aliquots were taken from the supernatant solutions and analyzed by the two-phase titration method (Reid et al., 1967) modified for cationic surfactants using a $10^{-3} \mathrm{M}$ SDS solution as titrant (Sabah and Çelik, 2002). In this method the detection limit value for each surfactant is $\sim 1 \times 10^{-5} \mathrm{~mol} / \mathrm{L}$. The amount of surfactant adsorption onto clinoptilolite was calculated from the difference between initial and final solution concentrations. Blank tests carried out during adsorption revealed no adsorption of quaternary amines onto polycarbonate centrifuge tubes within the detection limit of the analysis technique used in this study.

\section{$\zeta$ potential measurements}

The $\zeta$ potential measurements were carried out with $\zeta$ Meter 3.0+ using the electrophoresis method (Leja, 1982). The Zeta Meter automatically calculates the electrophoretic mobility of the particles and converts it to the $\zeta$ potential using the Smoluchowski equation (Hunter, 1988). The clinoptilolite particles $-100 \mu \mathrm{m}$ in diameter were used during the measurements. After the adsorption tests using HDTMA, TDTMA and DDTMA, an aliquot of $\sim 25 \mathrm{~mL}$ was taken from the supernatant solution of each sample and placed in a Plexiglas electrophoresis cell. An appropriate amount of sample from the clinoptilolite bed was transferred into the electrophoresis cell. The $\zeta$ potential of ten particles for each sample was determined and their average was taken.

\section{Desorption}

$1 \mathrm{~g}$ of clinoptilolite and $20 \mathrm{~mL}$ of $2 \times 10^{-2} \mathrm{M}$ concentration HDTMA solution were put into $50 \mathrm{~mL}$ centrifuge tubes and conditioned for $2 \mathrm{~h}$ at $400 \mathrm{rpm}$ at room temperature. The tubes were centrifuged for $15 \mathrm{~min}$, and $2 \mathrm{~mL}$ of solution were removed from the tube, analyzed and replaced with $2 \mathrm{~mL}$ of clinoptilolite supernatant solution and again conditioned for another $1 \mathrm{~h}$. This process was continued for ten cycles. In each stage, the amount of HDTMA desorbed from the clinoptilolite surface was determined.

\section{RESULTS AND DISCUSSION}

Adsorption isotherms and $\zeta$ potential curves

The adsorption isotherms of quaternary ammonium cationic surfactants, HDTMA $\left[\mathrm{C}_{16} \mathrm{H}_{33}\left(\mathrm{CH}_{3}\right)_{3} \mathrm{~N}^{+}\right]$, TDTMA $\left[\mathrm{C}_{14} \mathrm{H}_{29}\left(\mathrm{CH}_{3}\right)_{3} \mathrm{~N}^{+}\right]$and DDTMA $\left[\mathrm{C}_{12} \mathrm{H}_{25}\left(\mathrm{CH}_{3}\right)_{3} \mathrm{~N}^{+}\right]$onto clinoptilolite are shown in Figure $1 \mathrm{a}$, and the $\zeta$ potential curves of clinoptilolite as a function of the equilibrium concentration $\left(C_{\text {eq }}\right)$ of these surfactants are shown in Figure 1b. The adsorption isotherms exhibit three regions with two critical equilibrium concentrations of $C_{1}$ and $C_{2}$ each indicating the break points in the $\zeta$ potential curves. These three different regions, i.e. Region $1\left(C_{\mathrm{eq}} C_{1}\right)$, Region $2\left(C_{1}\right.$ $\left.C_{\text {eq }} C_{2}\right)$ and Region $3\left(C_{\text {eq }} C_{2}\right)$ are explained below. As seen in Figure 1a, the rising branches of the adsorption isotherms shift down while the onset of plateau regions shifts to the right with a decrease in the chain length. As stated earlier, the most important two mechanisms responsible for cationic surfactant adsorption onto clinoptilolite are ion exchange and hydrophobic interaction. These mechanisms are shown schematically in Figure 2. Ion exchange is a stoichiometric chemical reaction between two phases with the electrical neutrality of each phase being maintained throughout the exchange process (Townsend, 1991) and the method can simply be considered as a special case of adsorption (Treybal, 1980). Ion exchange is also controlled mostly by coulombic attractive forces (Kunin and Myers, 1952). On the other hand, hydrocarbon chains in water can associate with each other in such a way that contact between water and the hydrophobic regions is minimized. This is known as hydrophobic interaction in the bulk solution and controlled by van der Walls forces (Leja, 1982; Gregory, 1989). Similar phenomena can, of course, occur between the chains and adsorbent surfaces (Israelachvili, 1992). 

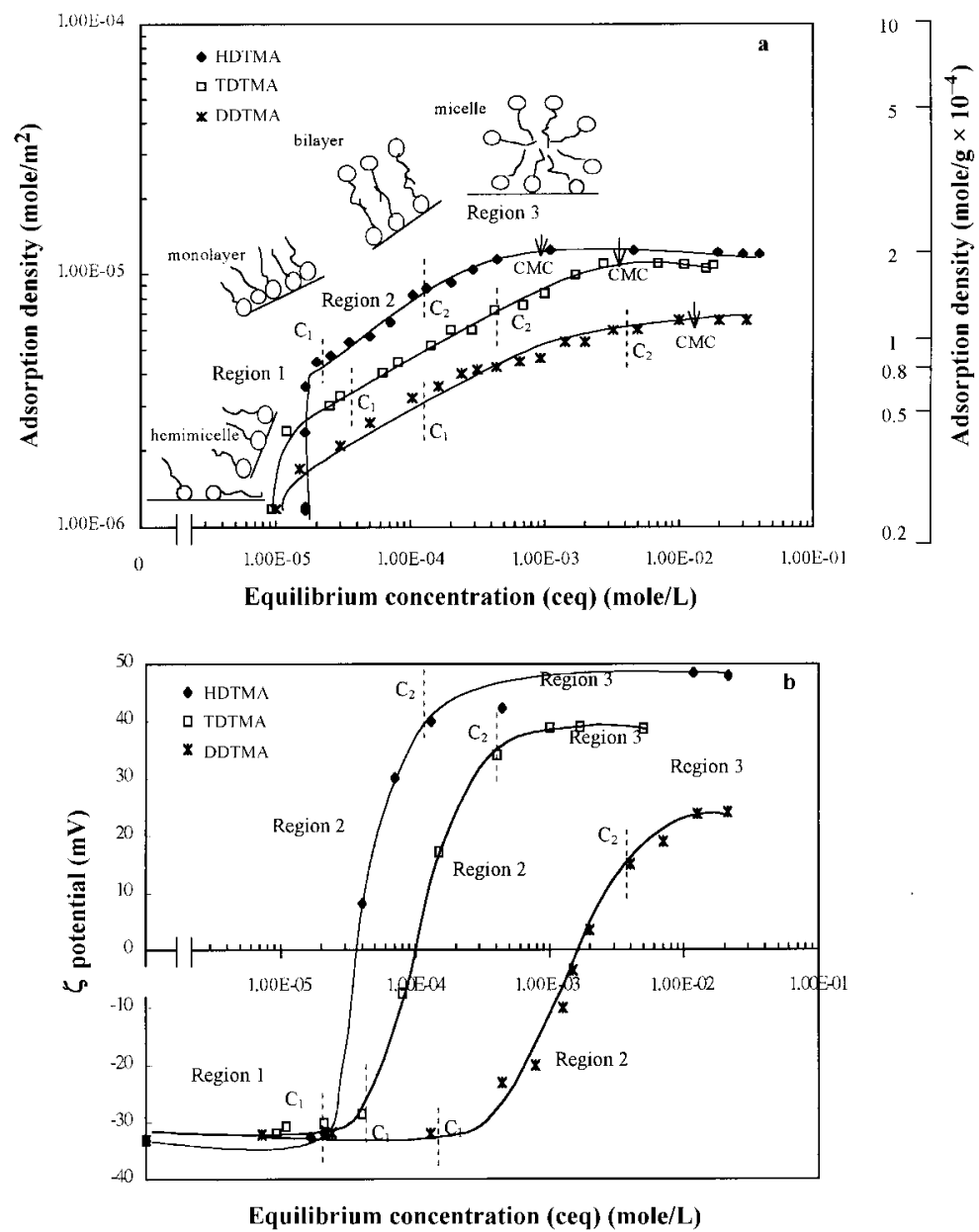

Figure 1. (a) Adsorption of the quaternary ammonium cationic surfactants with different hydrocarbon chain lengths onto clinoptilolite at $25^{\circ} \mathrm{C}$ and at $\mathrm{pH} 7.5-9$ (natural), and (b) variation of $\zeta$ potential of clinoptilolite $v s$. the concentration of the surfactant at $25^{\circ} \mathrm{C}$ and at natural $\mathrm{pH}$ of $7.5-9$.

Region $1\left(C_{e q}<C_{1}\right)$

In this region, indeed both adsorption mechanisms, ion exchange and hydrophobic (chain-chain, chainsurface) interactions, are operative. But, as will be explained below, adsorption resulting from the hydrophobic interactions tends to be complete at the offset of ECEC of clinoptilolite. It should be noted that since the organic cations HDTMA, TDTMA and DDTMA, which have large polar $\left(-\left(\mathrm{CH}_{3}\right)_{3} \mathrm{~N}^{+}\right)$groups, cannot enter into the clinoptilolite channels they can exchange only with the external cations of clinoptilolite, e.g. $\mathrm{K}^{+}, \mathrm{Ca}^{2+}, \mathrm{Na}^{+}$ and $\mathrm{Mg}^{2+}$. Therefore, it appears that due to the high ECEC of clinoptilolite, Region 1 is dominated by the ion-exchange mechanism alone. This is inferred from the $\zeta$ potential curves (Figure $1 \mathrm{~b}$ ) and the analysis of metal cations released into the solution from clinoptilolite during ion exchange. It is interesting to note that there is a significant adsorption of surfactants (Figure 1a), in the region where $\zeta$ potential remains almost constant at $\sim-33 \mathrm{mV}$ (Figure 1b). As mentioned earlier, the ion- exchange mechanism occurs in an equivalent amount of cations in order to maintain total electroneutrality which requires the $\zeta$ potential to remain constant throughout the exchange process. The results obtained by $\mathrm{Xu}$ and Boyd (1995) support this.

The equilibrium concentrations $\left(C_{1}\right)$ for HDTMA, TDTMA and DDTMA are $2.1 \times 10^{-5}, 4 \times 10^{-5}$ and $1.2 \times 10^{-4} \mathrm{~mol} / \mathrm{L}$, respectively, with corresponding adsorption densities of $4.8 \times 10^{-6}, 3.8 \times 10^{-6}$ and $3.2 \times 10^{-6} \mathrm{~mol} / \mathrm{m}^{2}$. The amount of HDTMA adsorption through the ion-exchange mechanism in this region is $\sim 95 \%$ of the ECEC of clinoptilolite and $\sim 74$ and $63 \%$ of the ECEC of clinoptilolite for TDTMA and DDTMA, respectively. Moreover, the slope of the HDTMA adsorption isotherm in this region is almost vertical and thus greater than that of TDTMA and DDTMA isotherms. Similar results were reported with adsorbents of ion exchange capability (Lee et al., 1989; Chen et al., 1998). This indicates that the HDTMA which has the longest hydrocarbon chain length of the three surfactants is more conducive to ion exchange. The diameter of the 
a Ion exchange mechanism

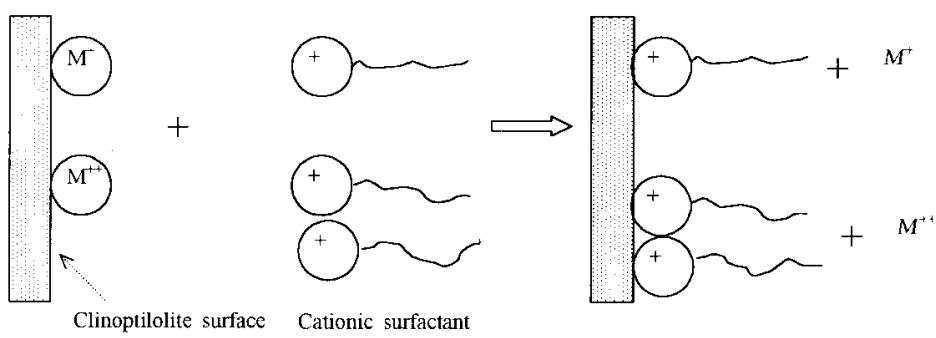

b Hydrophobic (chain-chain) interaction mechanism

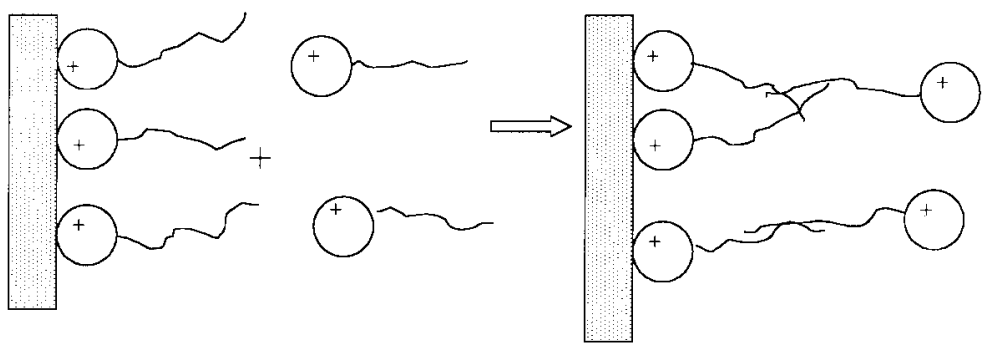

Figure 2. Diagrammatic representations of the adsorption mechanisms of the cationic surfactants at the clinoptilolite/water interface ( $M^{+}$and $M^{2+}$ are the mono and divalent cations of the external surface of clinoptilolite).

polar group is $6.94 \AA$ (Sullivan et al., 1997) with a cross-sectional area of $37.82 \AA^{2}$. Therefore, the adsorption of cationic surfactants with such a large polar group should occur only at the clinoptilolite/water interface, namely, in the EDL of the clinoptilolite particles. The value of $37.82 \AA^{2}$ has been taken into consideration to interpret the packing area of surfactant ions in adsorbed layers. The adsorption densities of HDTMA, TDTMA and DDTMA at their equilibrium concentrations of $C_{1}$ are $4.8 \times 10^{-6}, 3.8 \times 10^{-6}, 3.2 \times 10^{-6} \mathrm{~mol} / \mathrm{m}^{2}$ with the corresponding packing areas of $34.60,43.70$ and $51.90 \AA^{2}$, respectively. The corresponding surfactant adsorption in this region is $\sim 35-50 \%$ of the total adsorption. The packing areas indicate that the surfactant ions adsorb as a monolayer (Figure 1a) at the clinoptilolite/water interface at equilibrium concentrations of $C_{1}$. Considering the packing area value of $34.60 \AA^{2}$ for HDTMA, it is possible to assume that a bilayer adsorption started to form even before $C_{1}$. In summary, in this region (or below the ECEC), the hydrophobic interactions as well as ion-exchange mechanism operate at the clinoptilolite/water interface. Similar results have been pointed out by Sullivan et al. (1998a) as a result of the thermodynamic analysis of HDTMA adsorption onto clinoptilolite.

'Hemimicelle' is defined as 'the formation of twodimensional aggregates of surfactant ions at any solid surface or solid/liquid interface at surface coverages between 1 and $10 \%$ of a calculated monolayer' (Fuerstenau et al., 1964; Somasundaran and Fuerstenau, 1966). The Hemimicelle hypothesis has been often used to describe the unusual increase in the adsorption of ionic surfactants at the mineral/water interface (Somasundaran et al., 1964; Fuerstenau et al., 1964; Somasundaran and Fuerstenau, 1966; Xu and Boyd, 1995). Our results on the packing area values and the amount of surfactants adsorbed at the $C_{1}$ concentration may reveal that the hemimicelles for HDTMA, TDTMA and DDTMA form at equilibrium concentrations lower than $C_{1}$. Despite this assertion, the expected sharp increase in the $\zeta$ potential does not occur in this region (Figure 1b). While this appears to be in disagreement with a number of studies (Fuerstenau et al., 1964; Somasundaran and Fuerstenau, 1966), the results reported by $\mathrm{Xu}$ and Boyd (1995) on the vermiculite/HDTMA system are in agreement with ours. But they attribute the absence of a sharp increase in adsorption and $\zeta$ potential at the low equilibrium solution concentrations of the surfactants (e.g. $\left.C_{\mathrm{eq}}<C_{1}\right)$ to the swelling property of vermiculite. However, unlike vermiculite, clinoptilolite has a stable structure and does not swell. Thus, the absence of a sharp increase in clinoptilolite/HDTMA system mostly results from the large ECEC of clinoptilolite. The ECEC of clinoptilolite is $\sim 2.2$ times more than that of vermiculite. In addition, it is presumed that the high ECEC of clinoptilolite is the main reason for the disagreement with the literature (Somasundaran and Fuerstenau, 1966). In other words, in region 1 van der Walls attractive forces can be considered as the driving force for ion exchange in addition to attractive coulombic forces. Therefore, as opposed to other studies (Fuerstenau et al., 1964; Somasundaran and Fuerstenau, 1966), equation 3 is more appropriate than equation 2 in describing the 
cationic surfactant adsorption at the clinoptilolite/water interface in region 1.

$$
\begin{aligned}
\Gamma_{\mathrm{i}}^{+} & =2 r_{\mathrm{i}} c_{\mathrm{i}} \exp \left[-z e \psi_{\delta} / \mathrm{k} T\right] \\
\Gamma_{\mathrm{i}}^{+} & =2 r_{\mathrm{i}} c_{\mathrm{i}} \exp [-z e \xi / \mathrm{k} T] \\
\Gamma_{\mathrm{i}}^{+} & =2 r_{\mathrm{i}} c_{\mathrm{i}} \exp [-(z e \xi+n \phi) / \mathrm{k} T]
\end{aligned}
$$

where, $\gamma_{\mathrm{i}}$ is the adsorption density of organic cation $\mathrm{i}$ $\left(\mathrm{mol} / \mathrm{cm}^{2}\right), r_{\mathrm{i}}$ is the radius of the adsorbed cation $\mathrm{i}(\mathrm{cm})$, $c_{\mathrm{i}}$ is the bulk concentration of counterion $\mathrm{i}\left(\mathrm{mol} / \mathrm{cm}^{3}\right), z$ is the valence of $\mathrm{i}$ including the sign, $\psi_{\delta}$ is the potential of stern plane $\delta$ (volt), $\mathrm{k}$ is Boltzmann's constant, $T$ is the absolute temperature $(\mathrm{K}), n$ is the number of $\mathrm{CH}_{2}$ and $\mathrm{CH}_{3}$ groups in the hydrocarbon chain of organic cation i, $\phi$ shows the average free energy of transfer of 1 mole of $\mathrm{CH}_{2}$ groups from the aqueous environment into the hemimicelles. Because, the $\zeta$ potential measured at the shear plane is very close to the Stern potential $\left(\psi_{\delta}\right)$, it may be used instead of $\psi_{\delta}$ in equation 1 (Somasundaran et al., 1964; Leja, 1982). Equations 1, 2 and 3 are known as the Stern-Grahame model representing the adsorption of a counterion, i, in the Stern layer of EDL. While equations 1 and 2 are responsible only for adsorption through electrostatic forces, equation 3 indicates the contribution of both electrostatic and van der Walls forces.

In our study, even though there is no sharp increase at concentrations $<C_{1}$ in region 1 , the hemimicelle formation in region 1 was quantified by taking the natural logarithm of both sides of equation 3 and plotting it in Figure 3 .

$$
\ln C_{\mathrm{i}}=(\phi / \mathrm{k} T) n+\ln \left(\gamma_{\mathrm{i}} / 2 r_{\mathrm{i}}\right)+z e \xi
$$

Plotting the values of $C_{1} / 2$ (the value of $C_{1} / 2$ is selected in region 1 such that the existence of chainchain interactions between the adjacent surfactant ions and also hemimicelle has already occurred) vs. $n$ and using equation 4 yields a straight line with a slope equal to ' $\phi / 2.3 \mathrm{k} T$ '; the free energy change of the system during the removal of 1 mole of $\mathrm{CH}_{2}$ from aqueous phase to the hemimicelle phase $(\phi)$ comes out to be $0.44 \mathrm{k} T$ or $\approx 1.09 \mathrm{~kJ} / \mathrm{mol} \mathrm{CH}_{2}$ (Figure 3 ); this is in disagreement with the values of $2.5-2.7 \mathrm{~kJ} / \mathrm{mol} \mathrm{CH}_{2}$

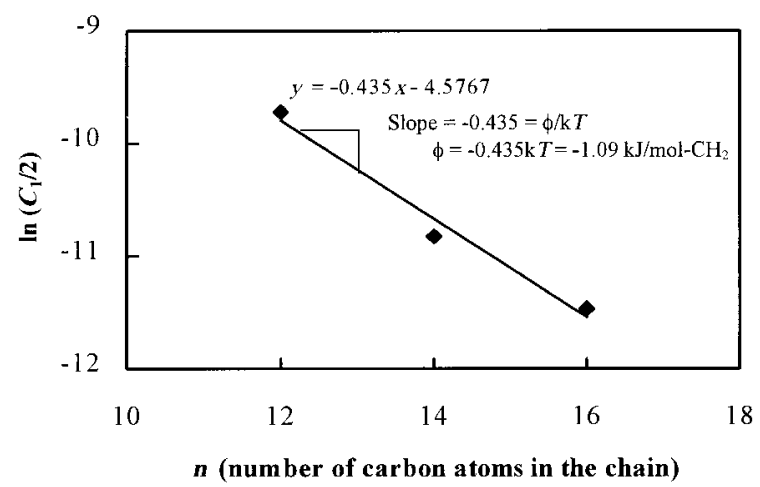

Figure 3. Variation of the $C_{1} / 2$ concentration of the cationic surfactant $v s$. the chain length. reported in the literature (Somasundaran et al., 1964; Fuerstenau et al., 1964). Despite this difference, it is stated that the hemimicelle formation occurs in Region 1 at concentrations $<C_{1}$ such as $C_{1} / 2$. Since, if the calculated $\phi$ value is very small or near zero, it signifies the absence of interactions between the chains of surfactants and that of hemimicelle formation.

\section{Region $2\left(C_{1}<C_{e q}<C_{2}\right)$}

The surfactant adsorption in this region is governed by the hydrophobic interactions between the surfactant chains. Sharp increases observed just after $C_{1}$ concentrations which correspond to the completion of ECEC of clinoptilolite in $\zeta$ potential curves are ascribed to the onset of bilayer adsorption in the EDL (Figure 1 a), the second layer possibly remaining in the diffuse layer. The sharp increases in the $\zeta$ potential curves are reflected in a narrow range of concentration for HDTMA and TDTMA while for DDTMA this occurs in a relatively wider range of concentration. The steady increases in adsorption isotherms in region 2 are seen more visibly for HDTMA and TDTMA than for DDTMA (Figure 1a). On further increase of surfactant adsorption in the EDL, the $\zeta$ potential of clinoptilolite reaches its isoelectric point (iep). The equilibrium concentrations at the iep of clinoptilolite for HDTMA, TDTMA and DDTMA are $3.2 \times 10^{-5}, 1 \times 10^{-4}$ and $1.7 \times 10^{-3} \mathrm{~mol} / \mathrm{L}$, respectively; this is in line with the ability of the longer chain length to undergo better hydrophobic interactions. The iep of the clinoptilolite/HDTMA system obtained in this study is almost the same as reported by $\mathrm{Li}$ and Bowman (1998). The adsorption densities of HDTMA, TDTMA and DDTMA at $C_{2}$ concentrations of $1.3 \times 10^{-4}$, $4.0 \times 10^{-4}$ and $3.7 \times 10^{-3} \mathrm{M}$, are $8.8 \times 10^{-6}, 6 \times 10^{-6}$ and $5.4 \times 10^{-6} \mathrm{~mol} / \mathrm{m}^{2}$, with packing areas of 18.90 , 27.68 and $30.76 \AA^{2}$, respectively. At higher surfactant concentrations, the surface sign of clinoptilolite is reversed from negative to positive and at $C_{2}$ the $\zeta$ potentials become $+40,+30$ and $+15 \mathrm{mV}$ for HDTMA, TDTMA and DDTMA, respectively. Haggerty and Bowman (1994) and Sullivan et al. (1997) suggested that bilayer adsorption in a clinoptilolite/HDTMA system occurs in two different modes: (1) with tail-totail adsorption of surfactant molecules at $C C_{\mathrm{CMC}}$; and (2) micelles with $C C_{\mathrm{CMC}}$ are rearranged as bilayers on clinoptilolite. As the packing areas for HDTMA, TDTMA and DDTMA, respectively, are 18.90, 27.68 and $30.76 \AA^{2}$ in region 2 , the bilayer adsorption is complete for HDTMA, but not for the other two surfactants.

Region $3\left(C_{e q}>C_{2}\right)$

Beyond $C_{2}$, a further increase in surfactant concentration results in a small increase in both adsorption and $\zeta$ potential values and the maximum adsorption densities coincide with the CMC values of the surfactants. The adsorption densities of HDTMA, TDTMA and DDTMA 


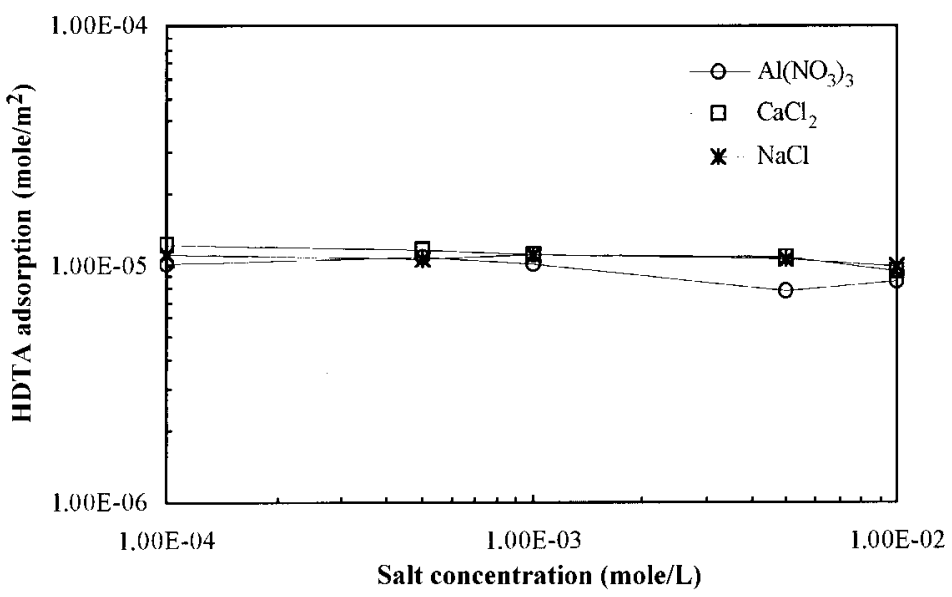

Figure 4. Effect of the mono and multivalent salts on the adsorption of the cationic surfactant onto clinoptilolite.

at the onset of plateaux occur at $1.22 \times 10^{-5}, 1.10 \times 10^{-5}$ and $6.58 \times 10^{-6} \mathrm{~mol} / \mathrm{m}^{2}$, respectively, with corresponding $\zeta$ potential values of $+48,+37$ and $+24 \mathrm{mV}$. Also, because the uptake of surfactant on clinoptilolite continues up to the $\mathrm{CMC}$ values, it may be an indication of micellar adsorption. Micellar adsorption of HDTMA on clinoptilolite examined by atomic force microscopy has been reported by Sullivan et al. (1997). Conversely, the formation of adsorbed micelles (also called admicelles) below the CMC value is possible (Elworthy and Mysels, 1966). The packing areas for each molecule of HDTMA, TDTMA and DDTMA at the maximum adsorption densities has been calculated as 13.62, 14.96 and $25.24 \AA^{2}$, respectively. Accordingly, while above the $C_{2}$ concentrations HDTMA and TDTMA molecules may adsorb onto clinoptilolite as multilayers or micelles, DDTMA molecules appear to adsorb as patchy bilayers.

\section{Effect of electrolytes on surfactant adsorption}

Figure 4 shows the effect of mono and multivalent electrolytes, i.e. $\mathrm{NaCl}, \mathrm{CaCl}_{2}$ and $\mathrm{Al}\left(\mathrm{NO}_{3}\right)_{3}$ on the adsorption of cationic surfactants at the clinoptilolite/ water interface at an initial HDTMA concentration of $1.5 \times 10^{-2} \mathrm{M}$. Figure 4 reveals that the HDTMA adsorption is constant until $1 \times 10^{-3} \mathrm{~mol} / \mathrm{L}$ of electrolyte concentration above which adsorption slightly decreases. The adverse effect of electrolytes on the cationic surfactant adsorption can be ascribed to the competition between the metal and organic cations for clinoptilolite. This effect is in the order of valency $\mathrm{NaCl} \mathrm{CaCl}_{2}$ $\mathrm{Al}\left(\mathrm{NO}_{3}\right)_{3}$. The most important decrease occurs in the presence of trivalent electrolyte $\mathrm{Al}\left(\mathrm{NO}_{3}\right)_{3}$, because of the greater specific affinity of $\mathrm{Al}^{3+}$ counterions to adsorb specifically onto clinoptilolite, i.e. in the IHP of the Stern layer of EDL as $\mathrm{Al}^{3+}$ form depending on the solution $\mathrm{pH}$ (Ersoy and Çelik, 2002). In addition, the adverse effect of metal ions on the adsorption of different organic cations onto different adsorbents has been reported (Beveridge and Pickering, 1983; Brownawell et al., 1990). On the other hand, the adsorption was found to be independent of solution $\mathrm{pH}$ in the range $4-10$.

\section{Desorption}

In order to see the stability of surfactant adsorbed onto clinoptilolite surface, desorption experiments with HDTMA in pure water were performed. As seen in Figure 5, after the second cycle the desorption of surfactant begins, and, at the end of the ninth cycle, $\sim 11 \%$ of the HDTMA is desorbed from the clinoptilolite surface. The desorbed surfactant ions from the second layer are configured as tail to tail. Thus, the bond strength of surfactant ions in the second layer is weaker than that of surfactant ions in the first layer. The former is realized by means of hydrophobic (chain-chain) interactions and the latter by the ion-exchange mechanism. Sullivan et al. (1997) using the thermogravimetric method showed that the HDTMA molecules adsorbed by ion exchange onto clinoptilolite are more stable than those adsorbed by the hydrophobic interaction mechanism. Also, in another study by Haggerty and Bowman (1994) it was shown that the adsorption of HDTMA on clinoptilolite by ion exchange is irreversible. It is also conceivable that the electrostatic repulsion between the

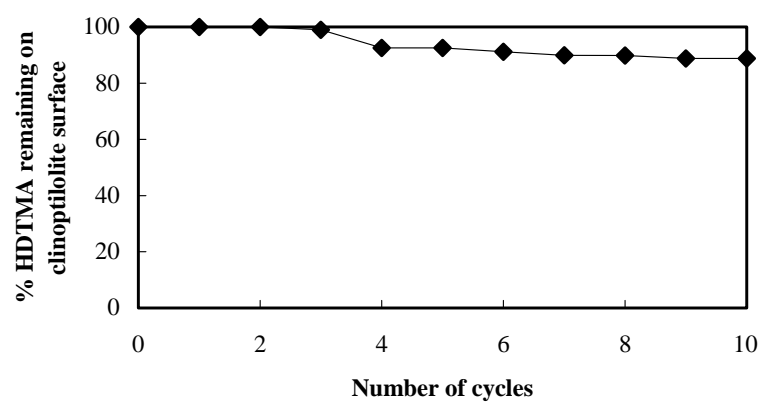

Figure 5. Desorption of HDTMA from the clinoptilolite surface. 
positively charged polar heads of the surfactants adsorbed in the second layer facilitates the desorption. The ionic strength is found to have a significant effect on the desorption of cationic surfactants from clinoptilolite and vermiculite surfaces (Xu and Boyd, 1995; Li et al., 1998). These studies indicate that the amount of HDTMA desorbed from these adsorbents in a medium of pure water is more than that desorbed in a medium of $\mathrm{CaCl}_{2}$, or with electrolytes of high ionic strength.

\section{CONCLUSIONS}

Although the adsorption of cationic surfactants with large polar groups $\left.\left(-\mathrm{CH}_{3}\right)_{3} \mathrm{~N}^{+}\right)$such as HDTMA, TDTMA and DDTMA occurs only in the EDL at the clinoptilolite/water interface, it is not conveniently described by the hemimicelle hypothesis. This probably results from the high ECEC of clinoptilolite used in this study. The extent of surfactant adsorption onto clinoptilolite through the ion-exchange mechanism constitutes $\sim 35-50 \%$ of the total adsorption. The free energy change $(\phi)$ for the removal of 1 mole of $\mathrm{CH}_{2}$ from the aqueous to the hemimicelle phase has been calculated as $1.09 \mathrm{~kJ} / \mathrm{mol}$.

The chain length of the surfactant affects the extent of both ion exchange and hydrophobic interactions at the clinoptilolite/water interface. Cationic surfactants with longer chains adsorb more than the shorter ones. HDTMA, which has the longest hydrocarbon chain length of the three surfactants, is more conducive to ion exchange. At high equilibrium concentrations, HDTMA and TDTMA ions appear to adsorb at the clinoptilolite/water interface as multilayers or micelles while DDTMA ions are envisaged to adsorb as patchy bilayers. However, at low concentrations, e.g. at the equilibrium concentration of $C_{1}$ corresponding to the offset of the ion-exchange mechanism, the surfactant ions adsorb as monolayer with the exception of HDTMA. Considering the calculated packing area of HDTMA, the bilayer adsorption of HDTMA starts to form even before $C_{1}$.

The presence of mono and multivalent salts in solution adversely affects adsorption above a certain salt concentration. These effects are in the order of valency $\mathrm{Al}\left(\mathrm{NO}_{3}\right)_{3}>\mathrm{CaCl}_{2}>\mathrm{NaCl}$.

\section{REFERENCES}

Ackley, M.W. and Yang, R.T. (1991) Diffusion in ionexchanged clinoptilolites. AIChE Journal, 37, 1645-1656.

Alberti, A. (1975) The crystal structure of two clinoptilolites. Tschermaks mineralogische und petrologische Mitteilungen, 22, 25-37.

Ames, L.L. (1960) The cation sieve properties of clinoptilolite. American Mineralogist, 45, 689-700.

Barrer, R.M., Paradopoulos, R. and Rees, L.V.C. (1967) Exchange of sodium in clinoptilolite by organic cations. Journal of Inorganic Nuclear Chemistry, 29, 2047-2063.

Beveridge, A. and Pickering, W.F. (1983) The influence of surfactants on the adsorption of heavy metal ions by clays Water Research, 17, 215-225.

Biswas, S.C. and Chattoraj, D.K. (1998) Kinetics of adsorption of cationic surfactants at silica-water interface. Journal of Colloid and Interface Science, 205, 12-20.

Blanchard, G., Maunaye, M. and Martin, G. (1984) Removal of heavy metals from waters by means of natural zeolites. Water Research, 18, 1501-1507.

Bowman, R.S., Haggerty, G.M., Huddleston, R.G., Neel, D. and Flynn, M. (1995) Sorption of Nonpolar organics, inorganic cations, and inorganic anions by surfactantmodified zeolites. Pp. 54-64 in: Surfactant Enhanced Remediation of Subsurface Contamination (D.A. Sabatini, R.C. Knox and J.H. Harwell, editors). ACS Symposium series 594, American Chemical Society, Washington, D.C.

Breck, D.W. (1974) Zeolite Molecular Sieves. John Wiley, New York, p. 771.

Brownawell, B.J., Chen, H., Collier, J.M. and Westall, J.C. (1990) Adsorption of organic cations to natural materials. Environmental Science \& Technology, 24, 1234-1241.

Çelik, M.S. and Yoon, R.H. (1991) Adsorption of Poly(oxyethylene)nonylphenol Homologues on a Low-Ash Coal. Langmuir, 7, 1770-1774.

Chen, G., Han, B. and Yan, H. (1998) Interaction of cationic surfactants with iron and sodium montmorillonite suspensions. Journal of Colloid and Interface Science, 201, $158-163$.

Elworthy, P.H. and Mysels, K.J. (1966) The surface tension of sodiumdodecylsulfate solutions and the phase separation model of micelle formation. Journal of Colloid and Interface Science, 21, 331-347.

Ersoy, B. (2000) Adsorption mechanisms of cationic surfactants onto clinoptilolite and removal of non-ionic organic contaminants by modified clinoptilolite (in Turkish). Ph.D. thesis, Istanbul Technical University, Istanbul, Turkey, pp. 212.

Ersoy, B. and Çelik, M.S. (2002) Electrokinetic properties of clinoptilolite with mono- and multivalent electrolytes. Microporous and Mesoporous Materials, 55, 305-312.

Flanigen, M. (1991) Zeolites and molecular sieves - an historical perspective. Pp. 13-35 in: Introduction to Zeolite Science and Practise (H. Van Bekkum, E.M. Flanigen and J.C. Jansen, editors). Elsevier, Amsterdam.

Fuerstenau, D.W., Healy, T.W. and Somasundaran, P. (1964) The role of the hydrocarbon chain of alkyl collectors in flotation. Transations AIME, 229, 321-325.

Gitipour, S., Bowers, M.T. and Bodocsi, A. (1997) The use of modified bentonite for removal of aromatic organics from contaminated soil. Journal of Colloid and Interface Science, 196, 191-198.

Gregory, J. (1989) Fundamentals of flocculation. Critical Reviews in Environmental Control, 13(3), 185-230.

Haggerty, G.M. and Bowman, R.S. (1994) Sorption of chromate and other inorganic anions by organo-zeolite. Environmental Science \& Technology, 28, 452-458.

Hayworth, J.S. and Burris, D.R. (1997) Nonionic surfactantenhanced solubilization and recovery of organic contaminants from within cationic surfactant-enhanced sorbent zones. 1. Experiments. Environmental Science \& Technology, 31, 1277-1283.

Hunter, J.R. (1988) Zeta Potential in Colloid Science, Principles and Applications, third printing. Academic Press, San Diego, p. 386.

Israelachvili, J.N. (1992) Intermolecular and Surface Forces. Academic Press Inc., San Diego, California.

Jaynes, W.F. and Vance, G.F. (1999) Sorption of benzene, toluene, ethylbenzene, and xylene (BTEX) compounds by hectorite clays exchanged with aromatic organic cations. Clays and Clay Minerals, 47, 358-365. 
Kunin, R. and Myers, R.J. (1952) Ion Exchange Resins. Wiley, New York.

Lee, J.F., Crum, J.R. and Boyd, S.A. (1989) Enhanced retention of organic contaminants by soil exchanged with organic cations. Environmental Science \& Technology, 23, $1365-1372$.

Leja, J. (1982) Surface Chemistry of Froth Flotation. Plenum Press, New York.

Li, Z. and Bowman, R.S. (1997) Counterion effects on the sorption of cationic surfactant and chromate on natural clinoptilolite. Environmental Science \& Technology, 31, 2407-2412.

Li, Z. and Bowman, R.S. (1998) Sorption of perchloroethylene by surfactant-modified zeolite as controlled by surfactant loading. Environmental Science \& Technology, 32, $2278-2282$.

Li, Z., Roy, S.J., Zou, Y. and Bowman R.S. (1998) Long-term chemical and biological stability of surfactant-modified zeolite. Environmental Science \& Technology, 32, $2628-2632$.

Merkle, A.B. and Slaughter M. (1968) Determination and refinement of the structure of heulandite. American Mineralogist, 53, 1120-1138.

Ming, D.W. and Dixon, J.B. (1987) Quantitative determination of clinoptilolite in soils by a cation-exchange capacity method. Clays and Clay Minerals, 35, 463-468.

Mortier, W.J. and Pearce, J.R. (1981) Thermal stability of the heulandite type framework: Crystal structure of the calcium/ ammonium form dehydrate at 483 K. American Mineralogist, 66, 309-314.

Narine, D.R. and Guy, D. (1981) Interactions of some large cations with bentonite in dilute solutions. Clays and Clay Minerals. 29, 205-212.

Neel, D. (1992) Quantification of BTX sorption to surfacealtered zeolites. Hydrology Open File Report No: H92-2, New Mexico Institute Of Mining and Technology.

Nzengung, V.A., Nkedi-Kizza, P., Jessup R.E. and Voudrias, E.A. (1997) Organic cosolvent effects on sorption kinetics of hydrophobic organic chemicals by organoclays. Environmental Science \& Technology, 31, 1470-1475.

Patzko, A. and Dekany, I. (1993) Ion exchange and molecular adsorption of a cationic surfactant on clay minerals. Colloids and Surface A: Physcochemical and Engineering Aspects, 71, 299-307.

Pavan, P.C., Gomes, G.A. and Valim, J.B. (1998) Adsorption of sodium dodecyl sulfate on layered double hydroxides. Microporous and Mesoporous Materials, 21, 659-665.

Reid, V.W., Longman, G.F. and Heinerth, E. (1967) Determination of anionic surface active detergents by two phase titration. Tenside, 4, No.9, 292-294.

Sabah, E. and Çelik, M.S. (2002) Adsorption mechanism of quaternary amines by sepiolite. Separation Science \&
Technology, 37, 3081-3097.

Sheng, G. and Boyd, S.A. (1998) Relation of water and neutral organic compounds in the interlayers of mixed $\mathrm{Ca} /$ trimethylphenylammonium-smectites. Clays and Clay Minerals, 46, 10-17.

Sheng, G. and Boyd, S.A. (2000) Polarity effect on dichlorobenzene sorption by hexadecyltrimethylammonium-exchanged clays. Clays and Clay Minerals, 48, 43-50.

Smith, J.A., Jaffe, P.R. and Chiou, C.T. (1990) Effect of ten quaternary ammonium cations on tetrachloromethane sorption to clay from water. Environmental Science \& Technology, 24, 1167-1172.

Somasundaran, P. and Fuerstenau, D.W. (1966) Mechanisms of alkyl sulfonate adsorption at the alumina-water interface. The Journal of Physical Chemistry, 70, 90-96.

Somasundaran, P., Healy, T.W. and Fuerstenau, D.W. (1964) Surfactant adsorption at the solid-liquid interface-dependence of mechanism on chain length. The Journal of Physical Chemistry, 68, 3562-3566.

Sridharan, A. and Satyamurty, P.V. (1996) Potential-distance relationships of clay-water systems considering the Stern Theory. Clays and Clay Minerals, 44, 479-484.

Sullivan, E.J., Hunter, D.B. and Bowman, R.S. (1997) Topological and thermal properties of surfactant-modified clinoptilolite studied by Tapping-Mode ${ }^{\mathrm{TM}}$ Atomic Force Microscopy and high-resolution thermogravimetric analysis. Clays and Clay Minerals, 45, 42-53.

Sullivan, E.J., Carey, J.W. and Bowman, R.S. (1998a) Thermodynamics of cationic surfactant sorption onto natural clinoptilolite. Journal of Colloid and Interface Science, 206, $369-380$.

Sullivan, E.J., Hunter, D.B. and Bowman, R.S. (1998b) Fourier Transform Raman Spectroscopy of Sorbed HDTMA and The Mechanism of Chromate Sorption to Surfactant-Modified Clinoptilolite. Environmental Science \& Technology, 32, 1948-1955.

Townsend, R.P. (1991) Ion Exchange in Zeolites Pp. 359-390 in: Introduction to Zeolite Science and Practice (H. Van Bekkum, E.M. Flanigen and J.C. Jansen, editors). Elsevier, Amsterdam.

Treybal, R.E. (1980) Mass Transfer Operations. Mc GrawHill, Inc., Singapore.

$\mathrm{Xu}$, S. and Boyd, S.A. (1995) Cationic surfactant sorption to a vermiculitic subsoil via hydrophobic bonding. Environmental Science \& Technology, 29, 312-320.

Zhu, L., Li, Y. and Zhang, J. (1997) Sorption of organobentonites to some organic pollutants in water. Environmental Science \& Technology, 31, 1407-1410.

(Received 19 March 2002; revised 8 November 2002; Ms. 642) 